\title{
DETERGENT AIDED REFOLDING AND PURIFICATION OF RECOMBINANT XIAP FROM INCLUSION BODIES
}

\author{
KATALIN NAGYa, ZITA KOVÁCS ${ }^{b}$, ILDIKÓ MIKLÓSSYc*, \\ PÁL SALAMON ${ }^{\mathrm{b}}$, CSONGOR-KÁLMÁN ORBÁN ${ }^{\mathrm{c}}$, \\ BEÁTA ALBERT ${ }^{\mathrm{b}, \mathrm{c}}$, SZABOLCS LÁNY|'
}

\begin{abstract}
Human proteins expressed in prokaryotic systems tend to form inclusion bodies. Proteins in inclusion bodies are inactive and the refolding of these densely packed protein molecules is affected by several factors depending on the applied refolding technique. To obtain the active form of protein the most common technique is denaturation of the protein aggregates followed by refolding of inclusion proteins. Conventional denaturants for solubilization are urea, guanidine hydrochloride and sodium dodecyl sulphate (SDS), while refolding can be achieved by several techniques found in the literature. In our study, the recombinant GST-tagged XIAP (X-linked Inhibitor of Apoptosis protein) construct was expressed as inclusion bodies. The protein was solubilized with high efficiency using $\mathrm{N}$-Lauroylsarcosine (ionic detergent). A chromatography-based method using different ratios of detergents was investigated for the refolding process. Batch mode affinity purification was successfully executed using Glutathione Sepharose 4B resin and TritonX100, n-octyl $\beta$-D-thio-glucopyranoside (OTG) and 3-[(3-cholamidopropyl) dimethylammonio]-1-propanesulfonate hydrate (CHAPS) detergents in the appropriate ratio. Finally, the refolded protein was purified by size-exclusion chromatography and investigated by western blot analysis.
\end{abstract}

Keywords: XIAP, inclusion body, solubilization, refolding, detergents, affinity chromatography

a University POLITEHNICA of Bucharest, Faculty of Applied Chemistry and Materials Science, Str. Gh. Polizu, Nr. 1-7, Sector 1, 011061 Bucuresti, Romania

b University of Pécs, Faculty of Sciences, Ifjúság útja 6., 7624 Pécs, Hungary

c SAPIENTIA Hungarian University of Transylvania, Faculty of Economics, Socio-Human Sciences and Engineering, Department of Bioengineering, 1 Libertatii Square, RO-530104, Miercurea Ciuc, Romania

${ }^{*}$ Corresponding author: miklossyildiko@uni.sapientia.ro 


\section{INTRODUCTION}

In multicellular organisms, apoptosis represents genetically programmed cell death. Apoptotic regulation has been involved in many human diseases, including cancer, autoimmune disease, inflammation and neurodegradation [1-3]. Discovering critical apoptosis regulators could be an efficient strategy for the development of new therapies. Two main apoptotic pathways are known: the intrinsic (mitochondrial) and the extrinsic pathways [4,5]. The two pathways are linked and the molecules in one pathway can influence the other pathway, while both proceed via activating caspases [6]. The most potent caspase inhibitor in the IAP family is human X-linked inhibitor of apoptosis protein (XIAP), contains 3 BIR domains (Baculovirus IAP Repeat) in the N-terminal region and a RING do-main endowed with E3 ubiquitin ligase activity, in the C-terminal region. The functional features of these structural domains have been studied in detail: BIR2 domain inhibits caspase- 3 and caspase-7, whereas BIR3 domain inhibits caspase-9. According to the literature high levels of e have been found in several cancer cell lines [7], while gene expression analysis of XIAP didn't show high level of mRNA [8]. This indicates that XIAP is probably regulated by post translational mechanisms. In this case, the physiological amount of Smac-DIABLO released from the mitochondria may not be sufficient to overcome the inhibitory effect of XIAP on the caspases, thus preventing apoptosis. Inactivation of overexpressed XIAP by Smac mimetic molecules may relieve caspase binding, thereby promoting apoptosis in malignant cells [9-17].

For over two decades, bacterial expression systems are useful in biotechnologies for investigation of biologically active human proteins, for development of therapeutic drugs and biomaterials [18]. The gram negative bacterium Escherichia coli (E.coli) is widely used for recombinant protein production. E. coli expression system remains the preferred host of choice being a well-established host with short culture time, cultivable on low cost media and characterized by easy genetic manipulation. The number of frequently used expression plasmid copies within the cell can range from one to several hundreds. Several studies have shown high expression levels of proteins using isopropyl b-D-1-thiogalactopyranoside (IPTG) inducible systems. The production process requires the accomplishment of three steps: expression, solubilization and purification [19]. However, when eukaryotic proteins are overexpressed in $E$. coli hosts, they often form inclusion bodies. XIAP is a cysteine rich protein (20 cysteines), moreover, containing a RING domain and increases its tendency to aggregation when overexpressed. 
Proteins in inclusion bodies are inactive and the refolding of these densely packed protein molecules is affected by several factors depending on the applied refolding technique. To obtain the active form of the target protein the most common technique is denaturing, then refolding of inclusion proteins. On one hand, conventional solubilizing denaturants are urea, guanidine hydrochloride and sodium dodecyl sulphate (SDS), and refolding of solubilized proteins several methods found in literature are used [18,20-25]. On the other hand, natively folded proteins can be extracted from inclusion bodies using mild detergents, such as $\mathrm{N}$-Lauroylsarcosine, known also as sarkosyl $L$ [26-29].This detergent has many desirable properties: it is nondenaturing, it forms micelles that are small in size, it does not interfere with spectroscopic concentration measurements, and it is of low cost. The refolding protocol developed by Massiah et al. is a rapid, simple, and efficient method for recovering glutathione S-transferase (GST) and Hisx6-tagged maltose binding protein (MBP) fusion proteins from inclusion bodies [30]. NLauroylsarcosine has a negatively charged carboxylate group similar to SDS, while it does not have a similar denaturing effect and it is used in many studies to solubilize proteins from inclusion bodies. Lysis buffers usually contain low percentages, $0.1 \%$ to $2 \%$, of $\mathrm{N}$-Lauroylsarcosine [31]. Mixed micelle systems are successfully used in detergent and mi-celle-assisted protein refolding procedures, the proposed mechanism of action being the simultaneous availability of transient polar and non-polar interaction sites which reduce hydrophobic interactions between folding intermediates [32]. Triton X-100 (4-(1,1,3,3-Tetramethylbutyl)phenyl-polyethylene glycol) is a non-ionic mild detergent used for cell lysis, cell membrane disruption and enhancing protein solubility [33]. CHAPS, namely 3-[(3-cholamidopropyl) dimethylammonio]-1-propanesulfonate is a zwitterionic detergent with nondenaturing properties used also for enhancing protein solubility. The above mentioned research group have observed that using both Triton X-100 and CHAPS in a specific ratio can enhance purification yield of sarcosyl solubilized proteins [29]. The exact mechanism of action of $\mathrm{N}$-Lauroylsarcosine, Triton $\mathrm{X}-100$ and CHAPS is not known, while on the basis of literature sources, it can be presumed that $\mathrm{N}$-Lauroylsarcosine molecules disrupt aggregation and encapsulate proteins, while Triton X-100 and CHAPS with low critical micelle concentrations ( $\mathrm{CMC}, 0.25 \mathrm{mM}$ and 6-10 mM) form large mixed micelles or bicelles that incorporate $\mathrm{N}$-Lauroylsarcosine molecules from the solution facilitating proper protein refolding [29].

The aim of our study was to develop a detergent and micelle-assisted, chromatography-based modified procedure for XIAP, and to investigate the effect of n-Octyl $\beta$-D-thioglucopyranoside (OTG) on protein refolding. 


\section{RESULTS AND DISCUSSION}

In our work, we present a straightforward solubilization and detergent assisted refolding procedure for the recovery of native recombinant GST tagged XIAP protein. XIAP contains a RING domain and 20 cysteine residues, and its GST-fusion construct is expressed in E. coli as inclusion bodies by standard expression protocols, which can be effectively solubilized by $\mathrm{N}$ Lauroylsarcosine according to our results. For the refolding of the protein, we used a detergent and micelle-assisted, chromatography-based modified procedure, which was optimized for XIAP and possibly, other RING domain containing proteins.

\section{Expression of GST-XIAP and solubilization with $\mathrm{N}$-Lauroylsarcosine}

For expression of the target GST-tagged XIAP recombinant protein, the E. coli BL21(DE3)Rosetta plysS strain was successfully used, the highest protein quantity being achieved at $18{ }^{\circ} \mathrm{C}$ in a 8 hours period, using $0.2 \mathrm{mM}$ inducer concentration [34]. The apparent molecular weight of the overexpressed protein was $80 \mathrm{kDa}$ based on SDS-PAGE analysis, consistent with the calculated molecular mass of the XIAP-GST construct $(78 \mathrm{kDa})$. Electrophoretic bands present in samples taken after (Figure 1. lane 2.) in comparison, to samples taken before (Figure 1. lane 1.) the induction of expression, analyzed by SDS-PAGE, provide confirmation of target protein expression. After cell lysis, the analyzed bacterial supernatant (Fig. 1, lane 3) and pelleted fraction (Fig. 1, lane 4), show the target protein aggregated in inclusion bodies. Natively folded proteins can be extracted from inclusion bodies using mild detergents such as $\mathrm{N}$-Lauroylsarcosine, in our case, in a first experiment, the solubilization step was carried out according to the protocol developed by Massiah's group [31]. The results suggest that virtually the total amount of the insoluble XIAP-GST was solubilized successfully at $10 \% \mathrm{~N}$-Lauroylsarcosine added to the lysis buffer. Figure 1. lane 6 . shows inclusion body supernatant after solubilization, while lane 7 . shows the pellet after solubilization.

Knowing that mild solubilization of inclusion body aggregates is the key for improving recovery of bioactive proteins, we continued our work with assessment of $\mathrm{N}$-Lauroylsarcosine concentration effect on solubilization yield of our target protein. The refolding protocol, based on the solubilization of proteins without chaotropic agents was optimized and used for the XIAP-GST construct. According to literature low concentrations of $N$-Lauroylsarcosine have been used to solubilize proteins expressed in bacteria grown in LB media $[35,36]$. In addition, Massia's grup concluded that GST tagged proteins expressed in bacteria grown in the M9 minimal medium, low concentrations $(0.3-2 \%)$ of $N$-Lauroylsarcosine are less effective [31]. We hypothesized that, 
less than $10 \%$ of $N$-Lauroylsarcosine will already be appropriate for solubilisation of inclusion bodies. Our results demonstrated that, decresing concentrations of $N$-Lauroylsarcosine from $2 \%$ to $4 \%$, as Figure 2. shows, we did not observe significant differences in total solubilized protein quantities. Based on our results, we can declare that solubilization with $2 \% N$-Lauroylsarcosine already was appropriate.

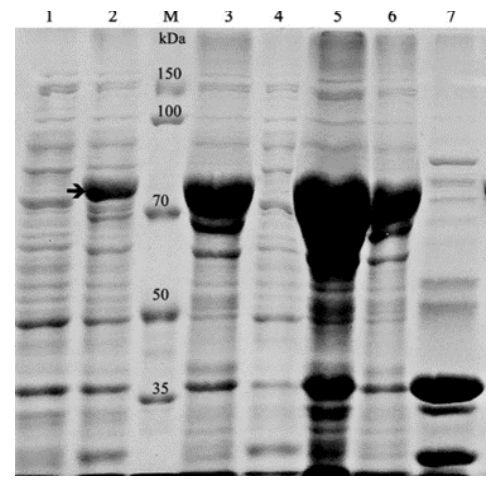

Figure 1. $10 \%$ SDS-PAGE analysis of XIAP-GST expressed in E. coli at $18{ }^{\circ} \mathrm{C}$ (Lane 1: uninduced total cell lysate; lane 2: total cell lysate afterinduction with $0.2 \mathrm{mM}$ IPTG after 8 hours of culture; lane M: Protein molecular weight marker (Novagen, Sigma Aldrich); lane 3: cell lysate after homogenization; lane 4: supernatant after centrifugation; lane 5: pellet after centrifugation; lane 6: supernatant after solubilization with $10 \% \mathrm{~N}$-Lauroylsarcosine; lane 7: pellet after solubilization. Proteins stained with Coomassie Brilliant Blue R250).

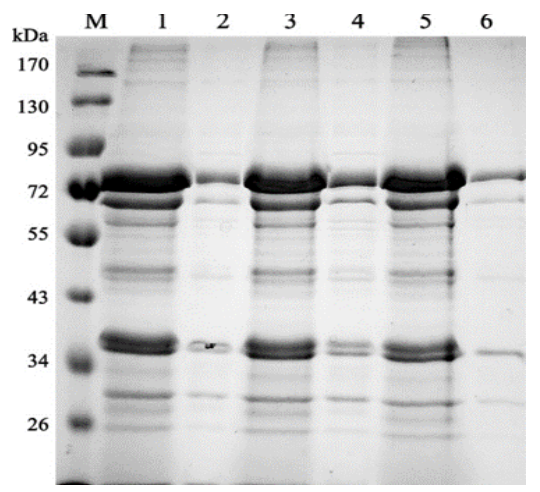

Figure 2. $10 \%$ SDS-PAGE analysis of solubilized XIAP-GST inclusion bodies with different concentration of $\mathrm{N}$-Lauroylsarcosine (Lane M: Protein molecular weight marker (Thermo Scientific); lane 1: 3\% N-Lauroylsarcosine supernatant; lane 2: 3\% $N$-Lauroylsarcosine pellet; lane 3: $4 \% \mathrm{~N}$-Lauroylsarcosine supernatant; lane 4: $4 \% N$-Lauroylsarcosine pellet; lane 5: $2 \% N$-Lauroylsarcosine supernatant; lane 6: $2 \% N$-Lauroylsarcosine pellet). 
Solubilized protein fractions were further analyzed by electrophoretic microchip using a 2100 Bioanalyzer and the Protein 230 kit for molecular weight determination and protein quantitation. As Fig. 3 shows, the apparent molecular weight of the target protein was about $80.4 \mathrm{kDa}$ based on the electrophoregram, consistent with the calculated molecular mass of the XIAP-GST construct $(78 \mathrm{kDa})$, while the solubilized XIAP-GST concentration is $1.025 \mu \mathrm{g} / \mu \mathrm{l}$. In total, we obtained $19.62 \mathrm{mg}(98.1 \%)$ solubilized XIAP-GST.

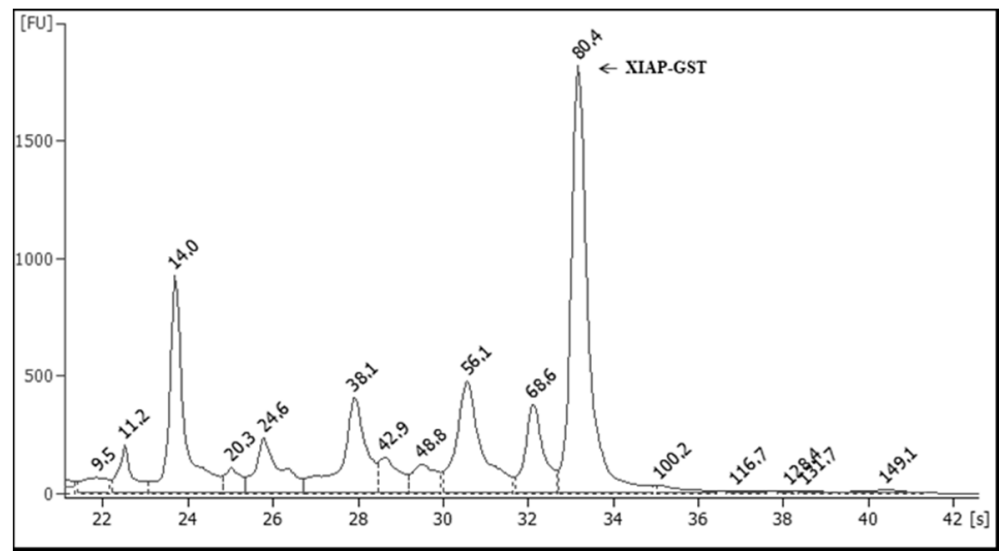

Figure 3. Protein electrophoretic microchip analysis of supernatant after solubilization with $N$-Lauroylsarcosine.

\section{Refolding the XIAP-GST protein by detergent-aided affinity chromatography and gel-filtration}

Removal of $N$-Lauroylsarcosine is necessary for efficient affinity purification and refolding of the target protein [37]. There are several studies in the literature for removal of $N$-Lauroylsarcosine by dilution and dialysis $[19,38]$. The CMC of $N$-Lauroylsarcosine is $>0.5 \%(14 \mathrm{mM})$ and at lower concentrations $(0.1-1 \%)$ it is removable by dialysis [33]. A low CMC indicates that the equilibrium between detergent monomers and detergent micelles is almost completely on the micelle side, and that the micelles are of large size, while only detergent monomers can diffuse easily into the surrounding buffer. Removal of detergents with $\mathrm{CMC}>5 \mathrm{mM}$ is not possible by dialysis. In addition, $N$-Lauroylsarcosine may be sequestered by adding a nonionic detergent, for example OTG, in at least a 5-fold weight excess over the $N$-Lauroylsarcosine [37].

Optimizing refolding conditions for the recombinant XIAP-GST was carried out by adding TritonX-100, CHAPS and OTG in the appropriate ratios, testing 6 different refolding conditions, as stated in the Materials and methods 
section (pairwise use of Triton X-100, CHAPS or OTG), prior to affinity purification performed in batch mode. All three detergents (TritonX-100, CHAPS and OTG) facilitated binding of the XIAP-fused GST to the GSH Sepharose matrix. No protein precipitation was observed in case of conditions 1, 2, 4, 5, 6 , while in case of condition 3 (Figure 3. lane 3), using the highest concentrations of TritonX-100 and $30 \mathrm{mM}$ CHAPS, almost the total amount of the target protein precipitated. Purification of the refolded protein was followed by SDS-PAGE as presented in Figure 4. Based on band widths of the purified fractions separated on SDS-PAGE gel, refolding aided by $2 \%$ Triton X-100 and 20\% CHAPS (Figure 4. lane 2) can be considered to be most adequate for XIAP-GST in our experimental setting. Except for refolding condition 3 , with $3 \%$ TritonX-100 and $30 \%$ CHAPS, in all other cases virtually all proteins were purified by affinity chromatography.

In summary, detergent aided refolding and purification experiments can be considered successful. The highest efficiency, i.e. $92.34 \%$ (3.02 mg) of refolded protein, was achieved using $2 \%$ TritonX-100 and 20 mM CHAPS. In terms of efficiency, refolding and purification performed with $1 \%$ Triton $\mathrm{X}$ 100 resulted in the next highest yield $-82.15 \%$ protein $(2.68 \mathrm{mg})$ with the addition of $10 \mathrm{mM}$ CHAPS, and $79.86 \%$ with $1.5 \%$ OTG $(2.61 \mathrm{mg})$. We recorded a slightly reduced efficiency, $73.03 \%$ refolded protein $(2.39 \mathrm{mg})$, in case of $1 \%$ TritonX-100 and $1 \%$ OTG, and $72.12 \%$ refolded protein $(2.36$ $\mathrm{mg}$ ) using $10 \mathrm{mM}$ CHAPS and 1\% OTG. Further purification protocol was performed using $2 \%$ TritonX-100 and $10 \mathrm{mM}$ CHAPS in order to obtain a high purity protein solution.

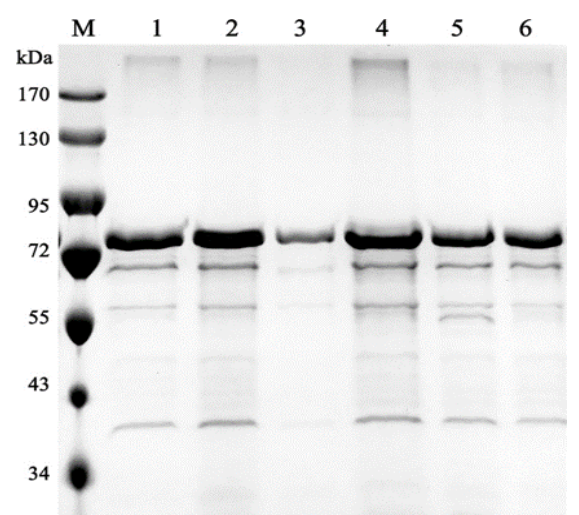

Figure 4. Batch purification of XIAP-GST protein refolded under different detergent-aided conditions (Lane M: Protein molecular weight marker (Thermo Scientific); lane 1: 1\% TritonX-100 and $10 \mathrm{mM}$ CHAPS; lane 2: 2\% TritonX-100 and 20mM CHAPS; lane 3: $3 \%$ TritonX-100 and 30mM CHAPS; lane 4: $1 \%$ TritonX-100 and 1\% OTG; lane 5: 1\% TritonX-100 and 1.5\% OTG; lane 6: 10 $\mathrm{mM}$ CHAPS and $1 \%$ OTG). 
However, based on our findings, several other tested conditions yielded similar refolding efficiencies, in a range of 92.34\%-72.12\% refolded XIAP-GST. Refolding conditions were tested in triplicates. Thus, for refolding of the protein, a detergent and micelle-assisted, chromatography-based procedure was established. The refolding procedure was carried out using different ratios of detergents, with affinity purification successfully executed using Glutathione Sepharose 4B resin and detergents in the appropriate ratios. These detergent mixtures (presented in Materials and Methods section) were set up as follows: from first to third mixture effectiveness of Triton- $X$ and CHAPS was investigated, then another non-ionic detergent (OTG) effect to protein refolding was tested by mixtures fourth and fifth. Based on our results in case of two non-ionic detergents we recorded a slightly reduced efficiency. Finally, we investigated CHAPS and OTG detergent mixtures as new potential refolding process.

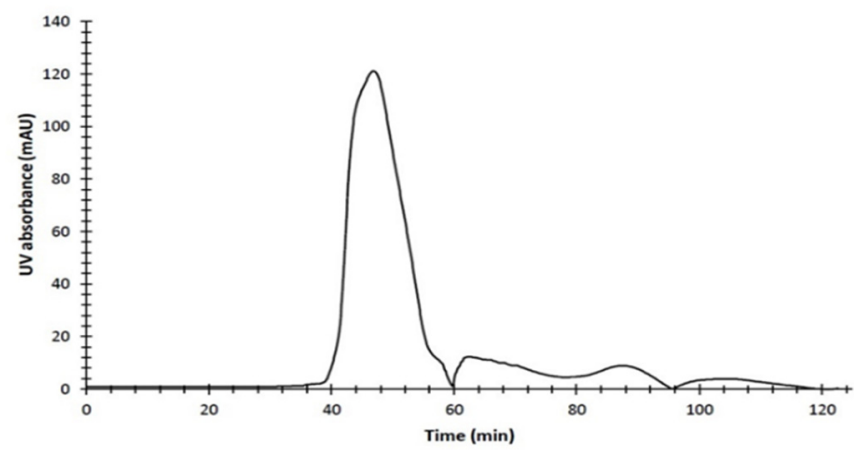

Figure 5. Elution profile of refolded XIAP-GST after separation on a HiLoad 16/600 Superdex $75 \mathrm{pg}$ column. Detection was performed at $280 \mathrm{~nm}$.

For further purification of the target protein we performed size-exclusion chromatography, using HiLoad 16/600 Superdex 75 pg column. The column was first loaded with Tris- $\mathrm{HCl}$ buffer, followed by sample injection to column. Figure 5. shows the elution profile of XIAP-GST, according to which, this purification step was very efficient, and resulted in a $97 \%$ efficiency purification of refolded protein. The overall yield of refolded protein was $17.57 \mathrm{mg} / 200 \mathrm{ml}$ E. coli culture.

\section{Identification of the refolded protein}

A WB analysis was performed to confirm the refolding of recombinant XIAP-GST. Western blot analysis indicated the authenticity of refolded and purified protein [39-41]. Proteins were immunodetected using an anti-XIAP 
antibody, which reacts with an epitope located in the C-terminal region encoded by amino acids $352-449$ of XIAP. The UBA region of the protein is responsible for interactions with e.g NFKB and other mono-or diubiquitiladed proteins [42].

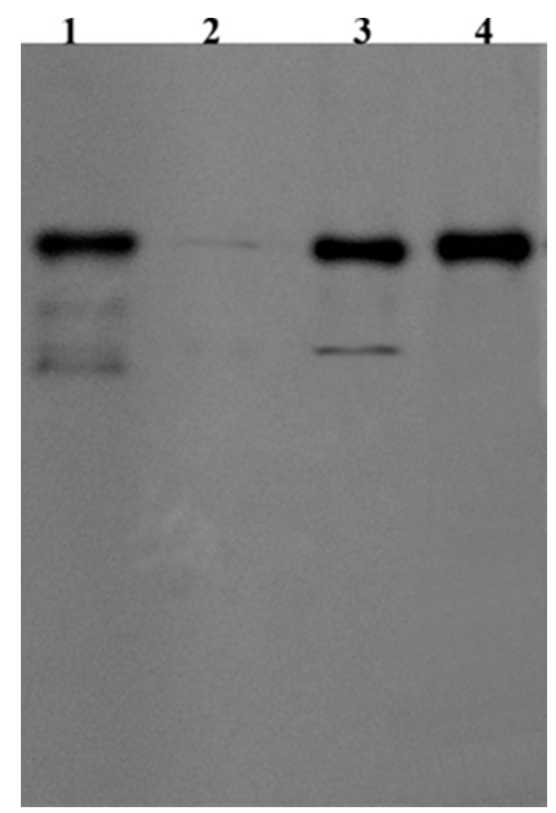

Figure 6. WB analysis of XIAP-GST protein. Lane 1: Refolded and purified XIAP-GST from experiment 2 (lane 2: unfolded GST-XIAP; lane 3: XIAPGST after size exclusion chromatography; lane 4: Recombinant XIAP-GST from commercial source).

Based on the above, we used western blotting to characterize structural epitopes of metastable folding intermediates, while the specificity of antibodies to folding intermediates allows to identify protein folding. As a control sample, recombinant XIAP-GST (84 kDa) obtained from commercial sources was used to identify our refolded protein. In addition, our blotting experiment was designed by using non-denaturing conditions. Fig. 6 shows the WB analysis of refolded XIAP-GST. As these results show, we can declare that solubilization and refolding of XIAP-GST was successful, as both the refolded protein and the commercial protein show similar profiles after separation and identification by the specific antibodies. In addition, in case of unfolded protein (Fig.6, lane 2.) there is no visible protein after western blotting, while this can also be considered as a proof that only refolded proteins were immunodetected. 


\section{CONCLUSIONS}

In vitro refolding of inactive protein aggregates is affected by several factors, depending on the applied refolding technique and in most cases, has to be customized for the specific protein. In our study, we present a quick and straightforward solubilization and detergent assisted refolding procedure using detergents for the recovery of native recombinant GST tagged XIAP protein.

According to the data presented above, XIAP-GST can be effectively solubilized by $2 \% \mathrm{~N}$-Lauroylsarcosine, while $92.34 \%$ of the protein can be refolded using $2 \%$ TritonX-100 and $20 \mathrm{mM} \mathrm{CHAPS}$ during affinity purification. However, Size-exclusion chromatography assured a purification of $97 \%$ of the refolded protein solution, thus obtaining an overall yield of $17.57 \mathrm{mg}$ refolded, purified XIAP-GST starting from $200 \mathrm{ml}$ bacterial culture.

\section{EXPERIMENTAL SECTION}

\section{Materials and instruments}

All molecular reagents and chemicals, unless stated otherwise, were purchased from commercial sources (Sigma Aldrich, Merck, BioLabs and Thermo Scientific ${ }^{\mathrm{TM}}$ ). E. coli BL21 (DE3) Rosetta plysS was obtained from Thermo Scientific. The pGEX6p1-GST-XIAP recombinant plasmid was a kind gift from Attila Reményi (Eötvös Loránd University, Budapest, Hungary) [43]. The recombinant GST-XIAP used as control for western blot analysis was obtained from commercial sources (Merck). The electrophoresis apparatus was from Bio-Rad (Bio-Rad Mini ProteanTetraCell). Sorvall LYNX 6000 super speed centrifuge (Thermo Scientific) was used for centrifugation. Batch purification of proteins was executed using Glutathione Sepharose 4B affinity chromatography resin (GE Healthcare). All chromatography experiments were performed using an AKTA FPLC system (Amersham Pharmacia Biotech). Hi Load 16/600 Superdex 75 pg column was purchased from GE Healthcare. For chip electrophoresis assays a 2100 Bioanalyzer Instrument (Agilent) and Protein 250 Kit (Agilent) were used.

\section{Protein expression and preparation of inclusion bodies}

The nucleotide sequence encoding XIAP (NM_001167.4) was fused with GST. The pGEX6p1-GST-XIAP recombinant plasmid was transformed into competent $E$. coli BL21 (DE3) Rosetta plysS cells and plated on Luria Bertani (LB) agar containing $100 \mu \mathrm{g} / \mathrm{ml}$ ampicillin and $34 \mu \mathrm{g} / \mathrm{ml}$ chloramphenicol. A single colony was used to inoculate $5 \mathrm{ml}$ LB-ampicillin medium and grown 
for $8 \mathrm{~h}$ at $37^{\circ} \mathrm{C}$ and $250 \mathrm{rpm}$ in an orbital shaker. Then, $1 \mathrm{ml}$ of the inoculum culture was transferred to $200 \mathrm{ml}$ of the M9 minimal medium containing 100 $\mu \mathrm{g} / \mathrm{ml}$ ampicillin and $34 \mu \mathrm{g} / \mathrm{ml}$ chloramphenicol and cultured under the same conditions until the $\mathrm{OD}_{600}$ value reached 0.7 . The culture temperature was decreased to $18^{\circ} \mathrm{C}$ and $0.2 \mathrm{mM}$ IPTG was added to induce the expression of the recombinant protein [34]. The culture was incubated for $8 \mathrm{~h}$ at $18^{\circ} \mathrm{C}$ in an orbital shaker. The cells were harvested by centrifugation at $4500 \mathrm{rpm}$ for $10 \mathrm{~min}$ at $4{ }^{\circ} \mathrm{C}$. Total protein was analyzed by $10 \%(\mathrm{w} / \mathrm{v})$ SDS-PAGE.

\section{Recovery of inclusion bodies}

Three grams of harvested cells were suspended in $30 \mathrm{~mL}$ lysis buffer (50 mM Tris HCl, $200 \mathrm{mM} \mathrm{NaCl}$ and $2 \mathrm{mM} \mathrm{DTT}$, pH 7.8). Lysozyme (1 mg/mL) was added to the cell suspension and incubated for 30 minutes at $4{ }^{\circ} \mathrm{C}$, in an orbital shaker. Afterwards, DNase I $(0.1 \mathrm{mg} / \mathrm{ml}$ final concentration) was added to the cell suspension. After 30 minutes of incubation, cells were homogenized with a high-pressure homogenizer (LM10 Microfluidizer) at 18,000 psi for two cycles. The cell lysate was centrifuged for 20 minutes at $15,000 \mathrm{x} \mathrm{g}$, at $4{ }^{\circ} \mathrm{C}$, and pellets were collected and washed with ultra-pure water twice.

\section{Solubilization of inclusion bodies}

Solubilization of the target protein was carried out by adding $\mathrm{N}$ Lauroylsarcosine in different concentrations $(2 \%, 3 \%, 4 \%$ and $10 \%)$ to the above mentioned lysis buffer. These suspensions were incubated at room temperature with gentle stirring for $1 \mathrm{~h}$, followed by centrifugation at $10,000 \times \mathrm{g}$ for $15 \mathrm{~min}$. The supernatant containing the target protein was immediately subjected to the refolding procedure. The solubilized protein fractions were analyzed by $10 \%(w / v)$ SDS-PAGE.

\section{Refolding and purification}

Qualitative analysis of total protein was executed by protein chip analysis. The experiment was carried out according to Protein 230 Kit (Agilent) experiment description using Bioanalyzer 2100. Optimizing refolding conditions for the recombinant XIAP-GST was carried out using TritonX-100, CHAPS and OTG in different ratios. Solubilized proteins were refolded using 6 different conditions, as follows:

1: $1 \%$ TritonX-100 and $0.61 \%(10 \mathrm{mM})$ CHAPS; $2: 2 \%$ TritonX-100 and $1.22 \%(20 \mathrm{mM})$ CHAPS; $3: 3 \%$ TritonX-100 and $4.83 \%$ (30mM) CHAPS; 4: $1 \%$ TritonX-100 and 1.5\% OTG; 5: $1 \%$ TritonX-100 and $1 \%$ OTG; 6 : 
$0.61 \%(10 \mathrm{mM})$ CHAPS and 1\% OTG. Refolding conditions were tested in triplicates. The detergents were added carefully to the solubilized protein with slow mixing, at room temperature. Refolded proteins were purified on Glutathione Sepharose 4B resin. Solubilized proteins were incubated for 2 hours with the glutathione beads at room temperature with gentle mixing. Purification of the refolded proteins was carried out according to the manufacturer's (GE Healthcare) instructions and was followed by $10 \%$ SDSPAGE. Elution of the protein was carried out by $50 \mathrm{mM}$ Tris-HCl buffer, $\mathrm{pH}$ 8.0 , containing $20 \mathrm{mM}$ reduced glutathione. The eluted fractions were stored at $4{ }^{\circ} \mathrm{C}$ and analyzed by $10 \%$ SDS-PAGE. Protein concentrations were determined spectroscopically (at $280 \mathrm{~nm}$ ) using Genova Nano micro-volume spectrophotometer. Purified proteins were dialyzed for $48 \mathrm{~h}$ in $50 \mathrm{mM}$ Tris$\mathrm{HCl}$ buffer, $\mathrm{pH} 7.8$ with three changes. For further purification of the target protein we performed by size-exclusion chromatography using a HiLoad $16 / 600$ Superdex $75 \mathrm{pg}$ column at $1 \mathrm{ml} / \mathrm{min}$ flow rate. The column was first loaded with 2 column volumes of $50 \mathrm{mM}$ Tris- $\mathrm{HCl}, \mathrm{pH} 7.8$ buffer, followed by sample injection. Elution was monitored at $280 \mathrm{~nm}$. The eluted fractions were stored at $4{ }^{\circ} \mathrm{C}$ and analyzed by $10 \%$ SDS-PAGE. All samples were analyzed by based the Laemmli protocol SDS-PAGE with a $5 \%(\mathrm{w} / \mathrm{v})$ stacking gel and a $10 \%(\mathrm{w} / \mathrm{v})$ resolving gel at a constant voltage of $120 \mathrm{~V}$ [44].

\section{Western Blot analysis}

Western Blot (Mini Trans-Blot ${ }^{\circledR}$, Bio-Rad) analysis was performed to confirm the refolding of XIAP-GST. Recombinant XIAP-GST proteins were separated by electrophoresis, using native PAGE and then transferred by wet transfer onto PVDF membrane. The transfer buffer contained $25 \mathrm{mM}$ Tris- $\mathrm{HCl}, 192 \mathrm{mM}$ glycine, $0.7 \%$ acetic acid at $\mathrm{pH}=7.4$. The membrane was incubated at $4^{\circ} \mathrm{C}$ overnight with a monoclonal anti-XIAP antibody, clone 2F1 (Abcam), at a dilution rate of 1:1000 in TBS buffer. After washing 4 times with TBS for 15 min each, the membrane was incubated with Goat Anti-Mouse IgG H\&L (HRP) secondary antibody (Abcam) diluted 1:1000 in TBS. The next step was washing 4 times with TBS for 15 min each. Finally, the protein was detected using the Pierce ${ }^{\mathrm{TM}}$ ECL substrate (Thermo Scientific), and the membrane was visualized using X-ray film (dark room technique).

\section{ACKNOWLEDGMENTS}

This research was financially supported by the Department of Bioengineering, Sapientia Hungarian University of Transylvania. 
DETERGENT AIDED REFOLDING AND PURIFICATION OF RECOMBINANT XIAP FROM ...

\section{REFERENCES}

1. C.M. Croce; J.C. Reed; Cancer Res., 2016, 76, 5914-5920

2. M.J. Roy; A. Vom; P.E. Czabotar; G. Lessene; Br. J. Pharmacol., 2014, 171, 1973-1987

3. R. Singh; A. Letai; K. Sarosiek; Nat. Rev. Mol. Cell Biol., 2019, 20, 175-193

4. P.J. Burke; Trends in Cancer., 2017, 3, 857-870

5. F. Cairrao; P.M. Domingos; Encycl. Life Sci. (ELS), John Wiley Sons, Ltd Chichester., 2010, pp. 1-8

6. Y. Estornes; M.J.M. Bertrand; Semin. Cell Dev. Biol., 2015, 39, 106-114

7. R. Saraei; M. Soleimani; A.A. Movassaghpour Akbari; M. Farshdousti Hagh; A. Hassanzadeh; S. Solali; Biomed. Pharmacother., 2018, 107, 1010-1019

8. P. Hundsdoerfer; I. Dietrich; K. Schmelz; C. Eckert; G. Henze; Pediatr Blood Cancer., 2009, 55, 260-266

9. H. Sun; L. Liu; J. Lu; S. Qiu; C.Y. Yang; H. Yi; S. Wang; Bioorganic Med. Chem. Lett., 2010, 20, 3043-3046

10. R. Feltham; B. Bettjeman; R. Budhidarmo; P.D. Mace; S. Shirley; S.M. Condon; S.K. Chunduru; M.A. McKinlay; D.L. Vaux; J. Silke; C.L. Day; J. Biol. Chem., 2011, 286, 17015-17028

11. G. Garg; S. Vangveravong; C. Zeng; L. Collins; M. Hornick; Y. Hashim; D. Piwnica-Worms; M.A. Powell; D.G. Mutch; R.H. Mach; W.G. Hawkins; D. Spitzer; Mol. Cancer., 2014, 13, 1-13

12. L. Bai; D.C. Smith; S. Wang; Pharmacol. Ther., 2014, 144, 82-95

13. A. Tchoghandjian; A. Soubéran; E. Tabouret; C. Colin; E. Denicolaï; C. JiguetJiglaire; A. El-Battari; C. Villard; N. Baeza-Kallee; D. Figarella-Branger; Cell Death Dis., 2016, 7, 1-10

14. S. Fulda; Clinical Cancer Research, 2015, 21, 5030-5037

15. L. Manzoni; D. Gornati; M. Manzotti; S. Cairati; A. Bossi; D. Arosio; D. Lecis; P. Seneci; Bioorganic Med. Chem. Lett., 2016, 26, 4613-4619

16. A.C. West; B.P. Martin; D.A. Andrews; S.J. Hogg; A. Banerjee; G. Grigoriadis; R.W. Johnstone; J. Shortt; Oncogenesis., 2016, 5, e216-6

17. K. Welsh; S. Milutinovic; R.J. Ardecky; M. Gonzalez-Lopez; S.R. Ganji; P. Teriete; D. Finlay; S. Riedl; S.I. Matsuzawa; C. Pinilla; R. Houghten; K. Vuori; J.C. Reed; N.D.P. Cosford; PLoS One., 2016, 11, 1-19

18. D.M. Francis; R. Page; Curr. Protoc. Protein Sci., 2010, 61, 5.24.1-5.24.29

19. H. Yamaguchi; M. Miyazaki; Biomolecules., 2014, 4, 235-251

20. E. Kovács; L. Szilágyi; G. Koncz; Appl. Biochem. Biotechnol., 2013, 170, 819830

21. C.J. Jeffery; Curr. Protoc. Protein Sci., 2016, 83, 29.15.1-29.15.15

22. A. Mohammadian; H. Kaghazian; A. Kavianpour; R. Jalalirad; Chem. Technol. Biotechnol., 2018, 93, 1579-1587

23. A. Basu; X. Li; S.S.J. Leong; Appl. Microbiol. Biotechnol., 2011, 92, 241-251

24. G. Gieseler; I. Pepelanova; L. Stuckenberg; L. Villain; V. Nölle; U. Odenthal; S. 
Beutel; U. Rinas; T. Scheper; Appl. Microbiol. Biotechnol., 2017, 101, 123-130

25. A.A. Padhiar; W. Chanda; T.P. Joseph; X. Guo; M. Liu; L. Sha; S. Batool; Y. Gao; W. Zhang; M. Huang; M. Zhong; Appl. Microbiol. Biotechnol., 2018, 102, 2363-2377

26. J. Zhang; X. Lv; R. Xu; X. Tao; Y. Dong; A. Sun; D. Wei; Appl. Microbiol. Biotechnol., 2015, 99, 6705-6713

27. K. Babaei Sheli; M. Ghorbani; A. Hekmat; B. Soltanian; A. Mohammadian; R. Jalalirad; Biotechnol. Reports., 2018, 19, e00259

28. A. Ghoshal; S.S. Ghosh; Appl. Biochem. Biotechnol., 2014, 175, 2087-2103

29. F. Naz; M. Asad; P. Malhotra; A. Islam; F. Ahmad; M.I. Hassan; Appl. Biochem. Biotechnol., 2014, 172, 2838-2848

30. H. Tao; W. Liu; B.N. Simmons; H.K. Harris; T.C. Cox; M.A. Massiah; Biotechniques., 2010, 48, 61-64

31. M.A. Massiah; K.M. Wright; H. Du; Curr. Protoc. Protein Sci., 2016, 84, 6.13.16.13.24

32. R.R. Burgess; Chapter 17 Refolding Solubilized Inclusion Body Proteins, in: Methods Enzymol., 1st ed., Elsevier Inc., 2009, pp. 259-282

33. G. Zardeneta; P.M. Horowitz; Anal. Biochem., 1994, 223, 1-6

34. K. Nagy; Z. Kovács; P. Salamon; C.K. Orbán; S. Lányi; B. Albert; Stud. Univ. Babes-Bolyai Chem., 2019, 64, 101-110

35. S. Frankel; R. Sohn; L. Leinwand; Proc. Natl. Acad. Sci. U. S. A., 1991, 88, 1192-1196

36. Q. Zhuo; J.H. Piao; R. Wang; X.G. Yang; Protein Expr. Purif., 2005, 41, 53-60

37. D. Kumar; Ref. Modul. Life Sci., 2018, 1-17

38. S.A. Frankel; A. Leinwand, Leslie; Solubilization of protein after bacterial expression using Sarkosyl,U.S. Patent, 1993, 1-5

39. D. Nasrabadi; S. Rezaeiani; A. Sayadmanesh; M.B. Eslaminejad; A. Shabani; Avicenna J. Med. Biotechnol., 2018, 10, 202-207

40. A.K. Patra; G.K. Gahlay; B.V.V. Reddy; S.K. Gupta; A.K. Panda; Eur. J. Biochem., 2000, 267, 7075-7081

41. W. Li; Y. Yuan; Z. Luo; X. Zheng; L. Zhao; W. Duan; Y. Yu; Biosci. Biotechnol. Biochem., 2010, 74, 1173-1180

42. M.K. Tse; S.K. Hui; Y. Yang; S.T. Yin; H.Y. Hu; B. Zou; B.C.Y. Wong; K.H. Sze; PLoS One., 2011, 12, e28511

43. A. Takeda; T.K. Oberoi-Khanuja; G. Glatz; K. Schulenburg; R. Scholz; A. Carpy; B. Macek; A. Remenyi; K. Rajalingam; EMBO J., 2014, 33, 1784-1801

44. U.K. Laemmli; Nature., 1970, 227 (5259), 680-685 